13

\title{
Электронно-эмиссионные свойства полупроводниковых субмикронных частиц
}

\author{
(С) М.В. Гавриков ${ }^{1}$, Н.Д. Жуков ${ }^{1}$, Д.С. Мосияш ${ }^{2}$, А.А. Хазанов ${ }^{2}$ \\ ${ }^{1}$ Саратовский государственный университет им. Н.Г. Чернышевского. Саратов, Россия \\ ${ }^{2}$ ООО „Рефр-Свет“, Саратов, Россия \\ E-mail: maks.gavrikov.96@gmail.com
}

Поступило в Редакцию 21 сентября 2018 г.

Исследованы свойства электронной эмиссии в субмикронных частицах полупроводников $\mathrm{Si}, \mathrm{GaAs}, \mathrm{InSb}$, InAs и их мультизеренных структурах. Установлено влияние свойств наночастиц на авто- и вторичную эмиссию. Предложен метод измерения коэффициента вторичной эмиссии полупроводников на основе метода сканирующей электронной микроскопии. Методом вакуумного триода исследовано влияние фотовозбуждения мультизеренной структуры полупроводниковых субмикронных частиц на их вторично-эмиссионные свойства.

DOI: 10.21883/PJTF.2019.01.47157.17532

Электронно-эмиссионные свойства полупроводниковых субмикронных частиц и наноструктур (авто-, фото-, вторичная эмиссия) лежат в основе действия ряда приборов: приборов вакуумной микроэлектроники, визуализаторов невидимых излучений, источников электромагнитных излучений в широком спектре (от рентгеновского до СВЧ). Актуальными при этом являются выбор материалов и оптимизация структур их использования.

Детальное исследование полевой эмиссии - эффективный инструмент для определения механизмов и параметров электронных процессов в объеме полупроводника и на поверхности с конкретной формой эмитирующих элементов. Особый интерес при этом представляют исследования методами сканирующей туннельной микроскопии (СТM), которые позволяют провести детальный анализ физических процессов $[1,2]$. В работах $[3,4]$ методом ВАХ-СТМ (ВАХ - вольт-амперная характеристика) нами были найдены параметры приповерхностных электронных состояний и установлено, что автоэмиссия в наночастицах узкозонных полупроводников является низкополевой: как минимум на порядок ниже, чем для металлов и углеродных наноструктур. В [5] исследован и обоснован оптимальный вариант автокатода. В продолжение этих публикаций в настоящей работе представлены результаты исследований вторичной эмиссии на субмикронных мультизеренных структурах наиболее применяемых полупроводников: $\mathrm{Si}, \mathrm{GaAs}, \mathrm{InSb}$, InAs.

Используемые в работе субмикронные частицы изготавливались из монокристаллических полупроводников электронного типа проводимости путем их измельчения в шаровой мельнице с последующей седиментацией для получения субмикронных размеров [6]. Частицы наносились на подложки из суспензии методом самоорганизации на поверхности при контролируемом испарении растворителя [7]. Толщина слоя покрытия составляла $\sim 2 \mu \mathrm{m}$. Средние размеры исходных частиц $0.2-0.4 \mu \mathrm{m}$. На рис. 1 представлено изображение поверхности исследуемых образцов, полученное методом СТМ.
Исследование морфологии поверхности и вольт-амперных характеристик методом СТМ осуществлялось с помощью сканирующего зондового микроскопа Nanoeducator-2-NT-MDT. Перед исследованием туннельной BAX отдельных частиц проводилось сканирование поверхности слоя в режиме стабилизированного тока. После анализа полученного СТМ-образа поверхности образца выбиралось не менее 10 точек для снятия ВАХ. В автоматическом режиме измерялись не менее десяти BAX на точку. Измерения ВАХ проводились в пределах величин тока от $10^{-11}$ до $10^{-8} \mathrm{~A}$ и напряжения от 0 до $5 \mathrm{~V}$. По воспроизводимости результатов измерений отбирались точки с устойчивыми характеристиками, после чего BAX усреднялись. Результаты измерений обрабатывались по общепринятым методикам сканирующей зондовой микроскопии полупроводниковых наноструктур [2]. При измерениях в области нуля для случая эмиссии электронов из зонда в образец („отрицательный потенциал на зонде относительно образца“)

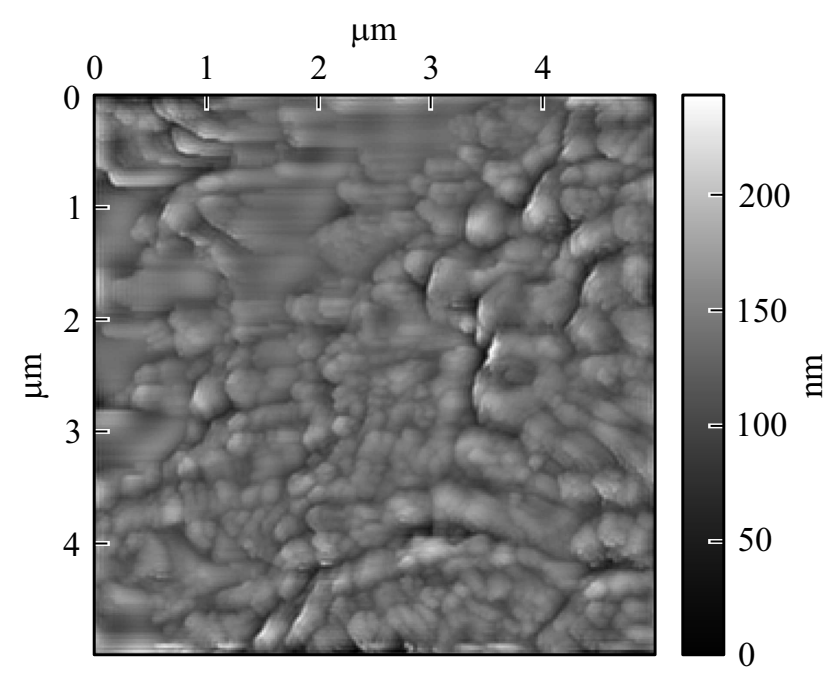

Pис. 1. СТМ-топограмма мультизеренной структуры GaAs. 

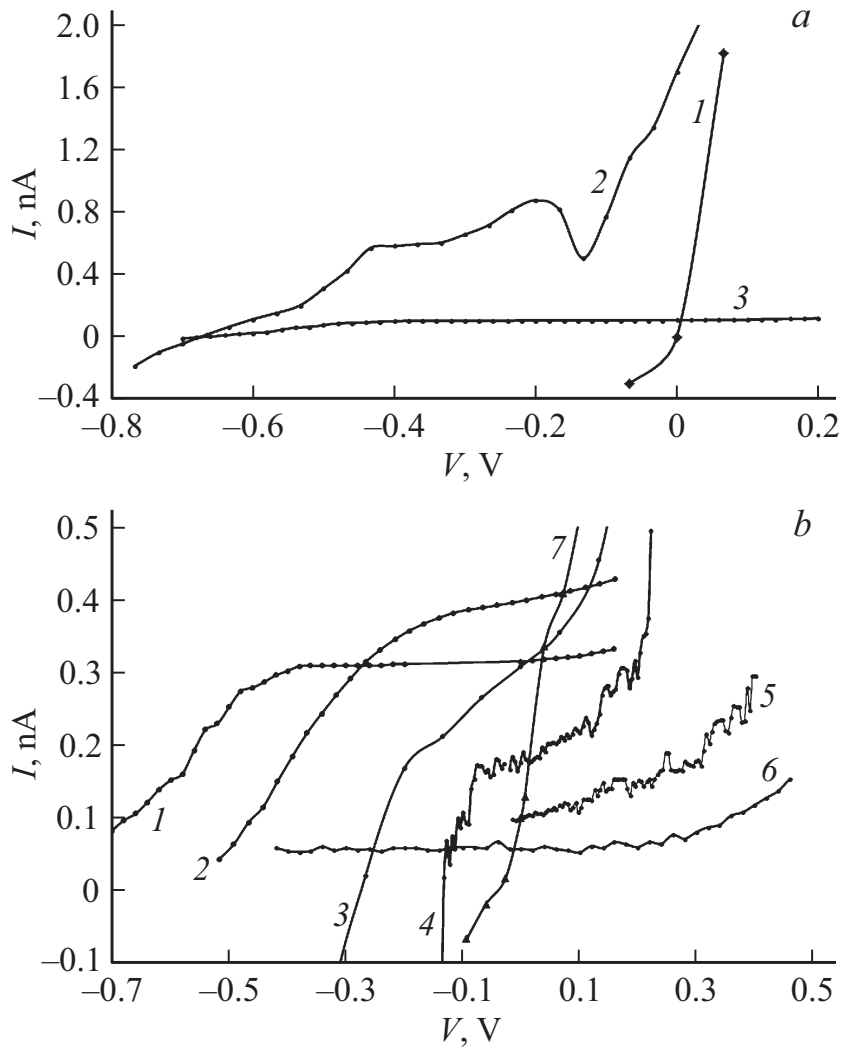

Pис. 2. $a-\mathrm{CTM}-\mathrm{BAX}$ образца InAs при величинах зазора зонд-образец $0(1), 3$ (2) и $5 \mathrm{~nm}(3) ; b-$ СТМ-ВАХ образцов InAs (1), InSb (2), Si (3), GaAs (4-6), InSb с засветкой (7).

на всех исследуемых образцах наблюдается аномальное поведение: ток обратного направления, нулевой ток при ненулевом напряжении, нулевое напряжение при ненулевом токе (рис. 2, a). Наблюдаемый эффект сильно зависит от величины зазора (рис. 2,a): при отсутствии зазора его нет, с увеличением зазора он проявляется, а с дальнейшим увеличением заметно уменьшается. При освещении указанный эффект заметно снижается либо исчезает (рис. 2, $b$ ), при исследовании на проводящем образце (слой ITO) не проявляется.

На образцах различных полупроводников эффект проявляется по-разному (рис. 2, $b$ ): на $\mathrm{Si}, \mathrm{InSb}$ и InAs стабильно, на GaAs - нестабильно, с различным характером поведения BAX. При этом на InSb и InAs эффект значительнее, чем на $\mathrm{Si}$ и GaAs.

Насколько нам известно, данные, связанные с проявлением подобного эффекта при СТМ-измерениях, в литературе отсутствуют. Объяснение наблюдаемого явления дано нами в модели вторичной эмиссии. Вылетевшие из зонда электроны, ускоренные полем в зазоре, попадают в образец, рождая вторичные электроны, которые веером разлетаются в сторону зонда. Бо́льшая часть вторичных электронов возвращается в образец под действием поля в зазоре, являющегося для них тормозящим. Однако как первичные, так и вторичные пролетающие в поле электроны изменяют конфигурацию поля, что способствует его ослабеванию вблизи линий их тока. Ввиду малой величины зазора (до $3 \mathrm{~nm}$ ) данный эффект может достаточно сильно влиять на токоперенос в системе зонд-зазор-образец. Помимо этого по нашим оценкам процесс токопереноса при данных величинах зазоров и тока происходит „Поэлектронно“ (за секунду через зазор проходит порядка $10^{9}$ электронов, однако они преодолевают зазор за $\sim 10^{-14} \mathrm{~s}$ ). При попадании электрона на поверхность образца процесс компенсации заряда занимает около $10^{-9} \mathrm{~s}$, в это время тормозящее для вторичных электронов поле в зазоре заметно уменьшается или падает до нуля. Благодаря этим процессам части электронов удается попасть на зонд, при этом создается ток, противоположный по направлению току первичных электронов. При их равенстве суммарный ток обращается в нуль (на рис. 2 и 3, точки при $I=0$ ). Влияние величины зазора сказывается на характере распределения поля в нем. Ненулевые пересечения кривых оси тока при $V=0$ можно объяснить влиянием заряда „вернувшихся“ вторичных электронов на поверхность образца, компенсация которого требует времени, большего, чем время изменения режима измерения ВАХ. Этот эффект хорошо известен для случаев вторичной эмиссии с высокоомной поверхностью образца (эффект Мальтера) [8]. Без этого процесса ВАХ вели бы себя так, как показано на рис. 2, a (кривая 2): обратно
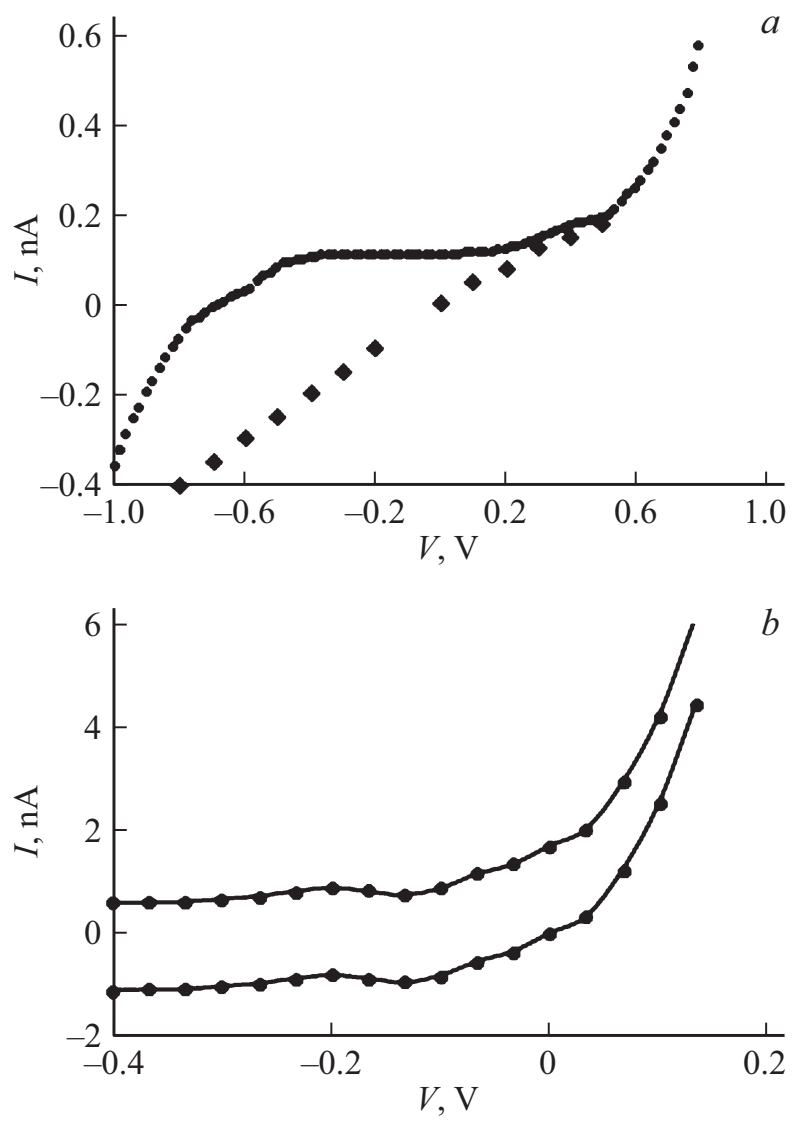

Рис. 3. Варианты экстраполяции ВАX (InAs) для вычислений коэффициента $\sigma$. Величины зазора, $\mathrm{nm}: a-5, b-3$. 
Сигналы переменной составляющей напряжения (в $\mathrm{mV})$

\begin{tabular}{c|c|c|c|c}
\hline Параметры воздействия & $\mathrm{GaAs}$ & $\mathrm{InSb}$ & $\mathrm{InAs}$ & $\mathrm{Si}$ \\
\hline$\lambda=385 \mathrm{~nm}, f=200 \mathrm{~Hz}$ & 100 & 10 & 25 & 80 \\
$\lambda=385 \mathrm{~nm}, f=1000 \mathrm{~Hz}$ & 30 & 5 & 10 & 50
\end{tabular}

направленный ток растет до некоторого значения, а затем падает до нуля, продолжая от нуля обратную ветвь ВАХ.

Влияние типа полупроводника сказывается поразному ввиду различных свойств проводимости поверхности [9]. Однако для материалов с суперлегкими электронами проводимости (InSb и InAs) определенным образом будет сказываться состояние электронной плазмы в приповерхностном слое, в частности эффекты локализации электронов и размерного квантования их энергии [3].

На рис. 3 приведены два варианта экстраполяции ВАХ для оценки коэффициента вторичной эмиссии $\sigma$ как отношения разницы тока к его величине. В обоих случаях максимальное значение коэффициента примерно равно двум. При этом учитывается лишь небольшая часть вторичных электронов, которым удается пролететь зазор с тормозящим полем. Поэтому истинный коэффициент вторичной эмиссии значительно больше. Такие высокие значения при относительно малых величинах напряжения (десятые доли вольта) можно объяснить значительным снижением работы выхода для приповерхностных электронов полупроводника благодаря действию сил изображения (величины поля более $10^{5} \mathrm{~V} / \mathrm{cm}$ ), а для узкозонных полупроводников - дополнительно эмиссией из локализованных уровней приповерхностного слоя [3].

В настоящей работе сделана попытка использования метода вакуумного триода с целью исследования влияния фотовозбуждения мультизеренной структуры полупроводниковых субмикронных частиц на их вторичноэмиссионные свойства. Измерения проводились на тестовых образцах, представляющих собой вакуумированный стеклянный баллон, в котором размещены прямонакальный оксидный катод, служащий источником первичных электронов; анод - слой металлизации на стекле баллона, на который наносился порошок исследуемого полупроводника; коллекторная сетка, размещенная между анодом и катодом параллельно плоскости анода, на которую подавалось положительное напряжение. Напряжение накала катода $U_{f}$ составляло $0.7-1 \mathrm{~V}$, ток эмиссии на сетку - 2-2.5 mA. Анод соединен с минусом источника питания сетки через резистор $1 \mathrm{M} \Omega$. Напряжение на коллекторной сетке $U_{g}$ выбиралось таким образом, чтобы после кратковременного подключения анода к плюсу источника питания сетки анод переходил в устойчивое состояние с $\sigma>1$. При этом на аноде устанавливается потенциал, несколько меньший, чем потенциал сетки. Разность потенциалов между анодом и сеткой в этом состоянии является характеристикой вторично-эмиссионных свойств анодного покрытия: при увеличении $\sigma$ разность потенциалов уменьшается (т.е. потенциал анода возрастает), и наоборот. Фотовозбуждение материала анодного покрытия проводилось светом с длиной волны $\lambda$ через стеклянную крышку прибора, модулированным излучением светодиодов мощностью около $1 \mathrm{~W}$. Частота модуляции регулировалась в пределах от 200 до $1000 \mathrm{~Hz}$. Сигналы переменной составляющей напряжения на аноде, возникающей вследствие облучения и характеризующей степень изменения коэффициента $\sigma$, измерялись с помощью осциллографа, подключенного к аноду через разделительную емкость.

Результаты измерений представлены в таблице, исходя из которой можно сделать заключение о том, что фотовозбуждение сказывается на вторичной эмиссии значительней для частиц широкозонных ( $\mathrm{Si}, \mathrm{GaAs})$ полупроводников, чем узкозонных (InAs, InSb), что можно объяснить их большей фоточувствительностью к излучению в синем спектральном диапазоне. Измерения в ближнем инфракрасном спектральном диапазоне $(\lambda=840 \mathrm{~nm})$ показали отсутствие изменений для всех вариантов полупроводников.

Таким образом, в работе были исследованы свойства электронной эмиссии в субмикронных частицах полупроводников $\mathrm{Si}, \mathrm{GaAs}$, InSb, InAs. Установлено наличие аномального явления - тока обратного направления при проведении СТМ-измерений ВАХ образцов. Объяснение наблюдаемого явления было дано нами в модели вторичной эмиссии. Определен коэффициент вторичной эмиссии, который оказался аномально большим (> 2). Методом вакуумного триода проведено исследование влияния фотовозбуждения мультизеренной структуры полупроводниковых субмикронных частиц на их вторично-эмиссионные свойства, показавшее, что большее влияние наблюдается для частиц широкозонных ( $\mathrm{Si}, \mathrm{GaAs}$ ) полупроводников, чем узкозонных (InAs, $\mathrm{InSb})$.

Исследование выполнено при финансовой поддержке РФФИ в рамках научного проекта № 17-07-00139.

\section{Список литературы}

[1] Миронов В.Л. Основы сканирующей зондовой микроскопии. М.: Техносфера, 2009. 144 с.

[2] Рыков С.A. Сканирующая зондовая микроскопия полупроводниковых материалов и наноструктур. СПб.: Наука, 2001. $52 \mathrm{c}$.

[3] Жуков Н.Д., Глуховской Е.Г., Мосияи Д.С. // ФТП. 2016. T. 50. В. 7. С. $911-917$.

[4] Жуков Н.Д., Глуховской Е.Г., Мосияш Д.С. // Письма в ЖТФ. 2015. Т. 41. В. 22. С. 1-7.

[5] Жуков Н.Д., Мосияш Д.С., Хазанов А.А., Абаньшин Н.П. // Прикладная физика. 2015. № 3. С. 93-97.

[6] Синев И.В., Тимошенко Д.А., Жуков Н.Д., Севостьянов В.П. // Нано- и микросистемная техника. 2018. Т. 20. № 8. C. 475-480. DOI: $10.17587 /$ nmst.20.475-480 
[7] Адрианов В.Е., Маслов В.Г., Баранов А.В., Федоров А.В., Артемьев М.В. // Опт. журн. 2011. Т. 78. № 11. С. 1-19.

[8] Шульман А.Р., Фридрихов С.А. Вторично-эмиссионные методы исследования твердого тела. М.: Наука, 1977. 551 с.

[9] Оура К., Лифиии В.Г., Саранин А.А., Зотов А.В., Катаяма М. // Введение в физику поверхности. М.: Наука, 2006. C. 116 . 